\title{
Digital transformation in cave mining
}

\author{
G Flores Newcrest Mining Limited, Australia
}

\begin{abstract}
Globally, safety and productivity are still the main concerns in the mining industry, particularly in operations using caving mining methods. Digital transformation is an approach to run the mining business more safely, profitably and sustainably. However, there are still several issues that are preventing the effective integration across the whole caving process. Digital transformation is the ability to "think and do" the cave mining business differently. The digital era enables not only having a connected mine to make quicker and better decisions to improve safety, productivity and profitability but also influences the organisations to make a transition from a reactive to a proactive, industrialised management approach. This would enable a more informed understanding and therefore increased control of the caving processes. In practice, this transformation will require the caving industry to move from a traditional, experience based, segmented operating model to an agile, integrated, dynamic, business value driven model, fostering a modern digital culture to ensure sustainable cave mining into the future. This paper, written to supplement a keynote address by the author, discusses how digital technologies will help cave mining change the way of doing business to reach new levels of performance across the caving process, particularly in more challenging mining conditions.
\end{abstract}

\section{Introduction}

Industry Revolution 4.0 is a term that originated from a German government initiative called "High-Tech Strategy 2020 Action Plan" in 2011 (Stock \& Seliger 2016). This term has been used in the manufacturing industry to describe the concept in which machines are augmented with wireless connectivity and sensors, connected to a system that can visualise the entire production line and make decisions on its own and in real time. Industry 4.0 describes the trend towards automation and data exchange in manufacturing technologies and processes which include smart sensors, the internet of things (IoT), big data, cloud computing, cognitive computing, machine learning, advanced analytics, and artificial intelligence.

With respect to mining, a similar concept is also being considered as illustrated in Figure 1, starting from its infancy when compared with other industries such as Digital Media and Retail which include Spotify, Mailonline, Amazon and Nexflix (Geraghty 2016).

Future mining is mainly going to use caving mining options extended into more challenging geotechnical conditions where safety, productivity, sustainability and profitability are the main innovation areas needed. Digital transformation will be the driver of the step change needed by the mining industry and especially the caving sector to deal with these challenges. This constitutes the "new cave mining era". To successfully manage this change in development, it will be a requirement for the cave mining industry to think differently, embrace disruption and step out of its current siloed, reactive and nonintegrated operational model. Smart sensors, connectivity, cloud computing, data analytics, power computers, visualisation and simulation have demonstrated the potential to improve the caving business with incomparable opportunities for value creation. 


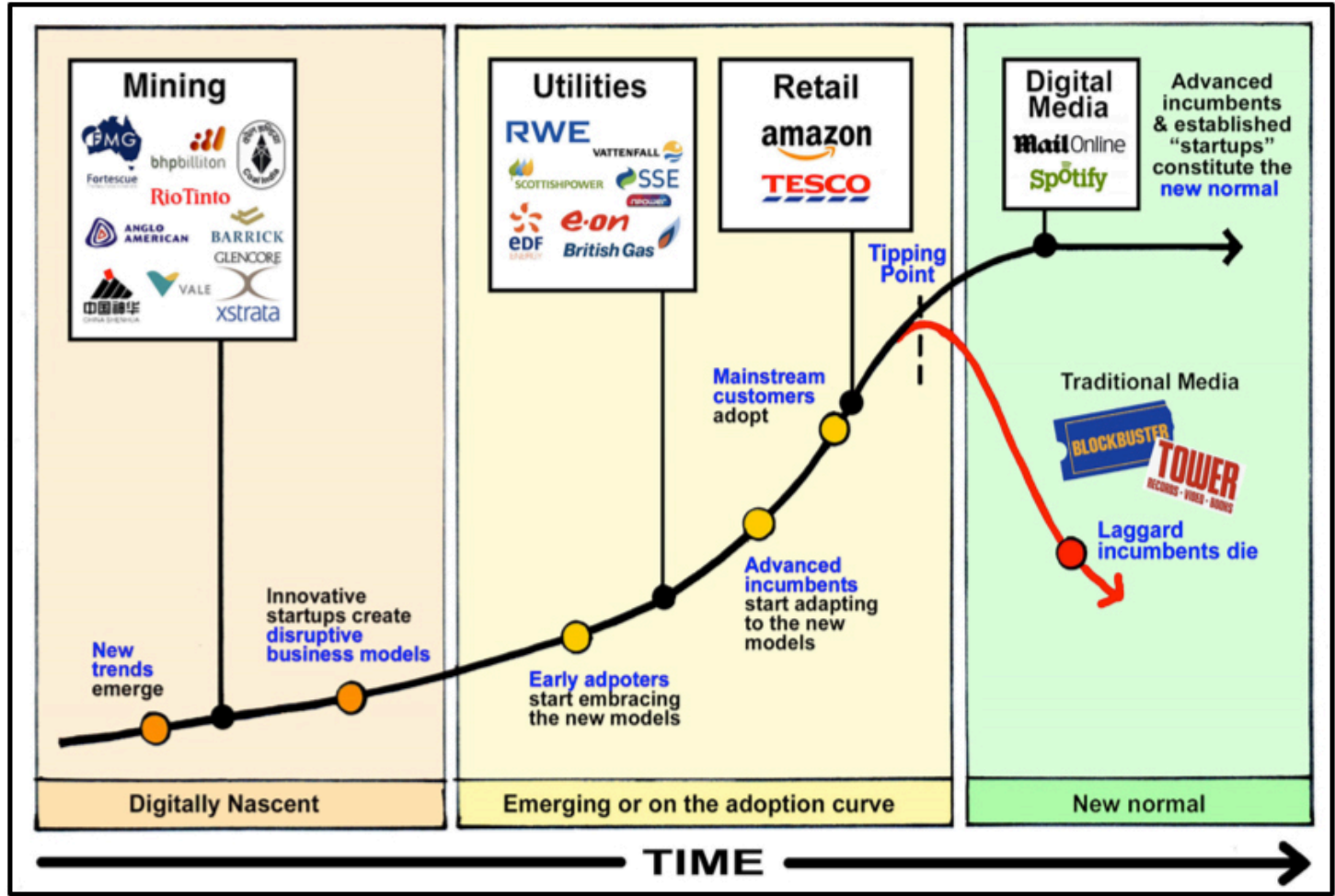

Figure 1 Mining lags well behind other industries on digital maturity (after Geraghty 2016)

The evolution of cave mining has been two-fold. The first has been the evolution of the equipment from manual to mechanization in order to effectively manage hard and big rocks for the purposes of improving safety and productivity. Various forms of equipment have been advanced to prototype stage waiting for early adopting into production. Examples of such equipment includes face drill rigs with up to four booms and remotely controlled, highly automated mechanical tunnel cutters, automated production drill rigs, hybrid and semi-autonomous load haul dump units, continuous loaders in conjunction with autonomous trucks. In addition, numerous adaptations of civil surface autonomous trucks are being made for underground applications.

The second cave mining evolution has been communications of data from verbal to analog to now digital in order to improve the decision making during all the stages of cave mining processes. There is considerable effort being made on data management including various forms of advanced sensors and Internet of Things (IoT). Most of these communications enabling technologies are still at early stage of development for cave mining applications.

The cave mining industry is now entering a new era where mining of strategic minerals will be in tough geotechnical conditions where the focus will continue to be on productivity, sustainability, profitability and more so on safety due to the depth of future orebodies. The opportunity is to achieve the goal of "Future of Cave Mining" through digital transformation which will provide the ability to "think and do" the cave mining business differently. This transformation enables making of informed decisions in real time. Collectively, these constitute what is referred to in this paper as operational model for future cave mining via digital transformation (Ernst \& Young 2018; Yeates 2017).

The roadmap towards digital transformation in cave mining is shown in Figure 2. It includes three models i.e. current operational model, enhanced operational model and digital operational model which are discussed next. 


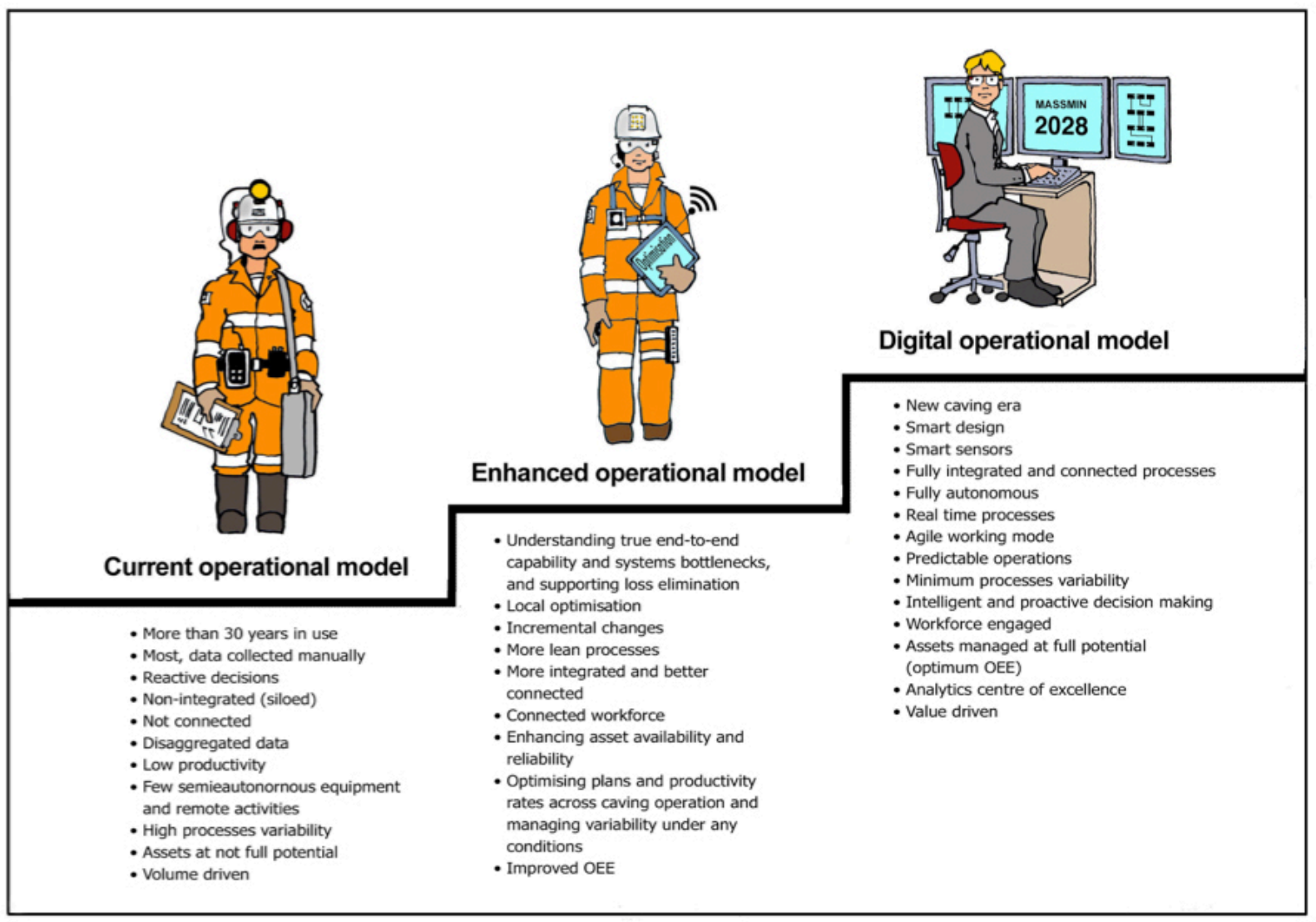

Figure 2 Digital transformation roadmap

\section{The roadmap towards digital transformation}

\subsection{Current operational model}

The current caving operational model, which has evolved over the last 30 years remains reactive, nonintegrated (siloed), not connected and informed decisions are not yet industrialised in real time.

The three main processes in cave mining are orebody access, cave establishment and cave production as illustrated in Figure 3 (Flores 2019). Orebody access includes the use of shafts and/or declines. Cave establishment is comprised of the use of preconditioning (hydrofracturing and confined blasting), footprint development (extraction, drawpoint and undercutting drives), infrastructure development (crusher chambers and ventilation), construction of civil works (roadways and drawpoint support), drawbell opening and undercutting. Cave production consists of material handling system from the drawpoints to the mill (loading, secondary rock breakage, crushing and conveying).

During the above processes, considerable data are collected. For example, in the cave establishment process data associated with preconditioning (Catalan 2015; Rojas \& Landeros 2017), development jumbos, boltec, meshing and shotcreting, explosives charging, loader and trucks as well as geological and geotechnical are collected. In cave production stage, data related to loaders, single boom jumbos and explosives, water cannon, rock breakers, crushers and conveyors or trucks or shafts performance are gathered. In addition, ore grade, fragmentation, drives convergence, seismicity, drawpoint status (e.g. hangups, fines, water, damage), draw and flow data are collected. 


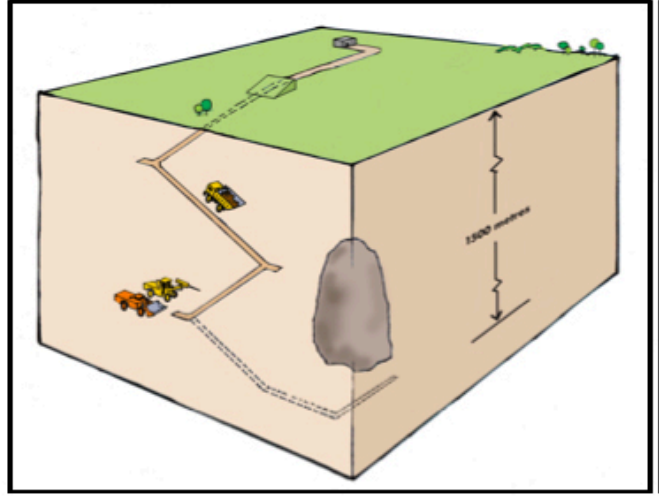

Orebody access

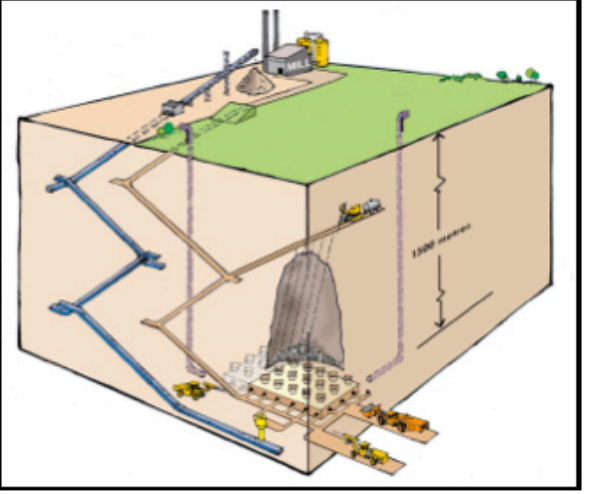

Cave establishment

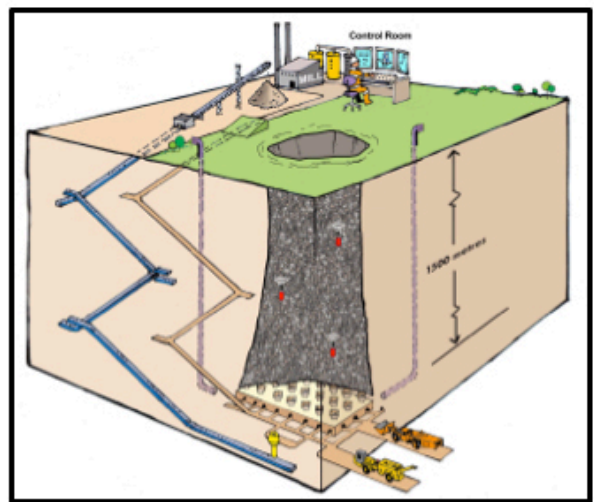

Cave production

Figure 3 Main caving processes - orebody access, cave establishment and cave production (Flores 2019)

Figure 4 is showing in general how the current operational model works. In summary it could say that the cave mining companies have typically made substantial investments in Operational Technology (OT) to gather data from their operations, measuring and monitoring some of the activities. However, these systems are typically individual 'apps', operate in isolation and are only visible in the mining control room, requiring a great deal of experience to make sense of the many screens, all with their own unique displays and user-interface (Accenture \& Avanade 2015).

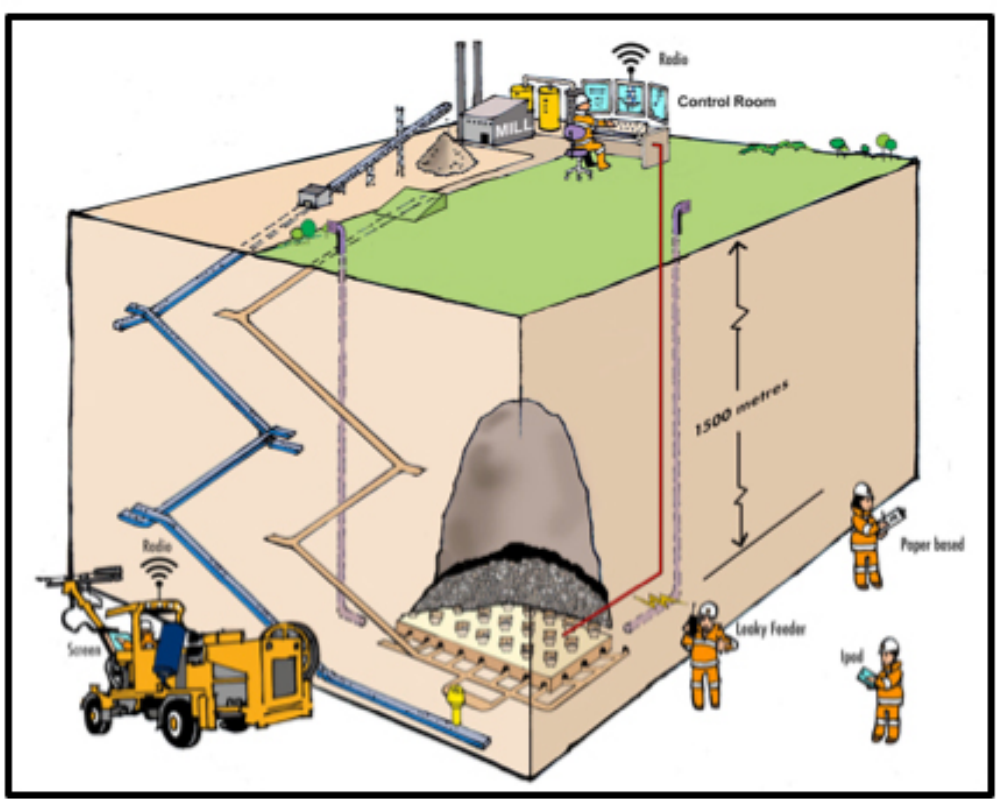

Figure 4 Current operational model 
There is a large amount of data needing to be collected during the cave mining processes yet, only a small portion of data $(<1 \%)$ is automatically collected, handled and analysed in real time (McKinsey\&Company 2015), as shown in Figure 5. This means the current operation model does not enable real time, optimisation of strategies for safety and productivity.

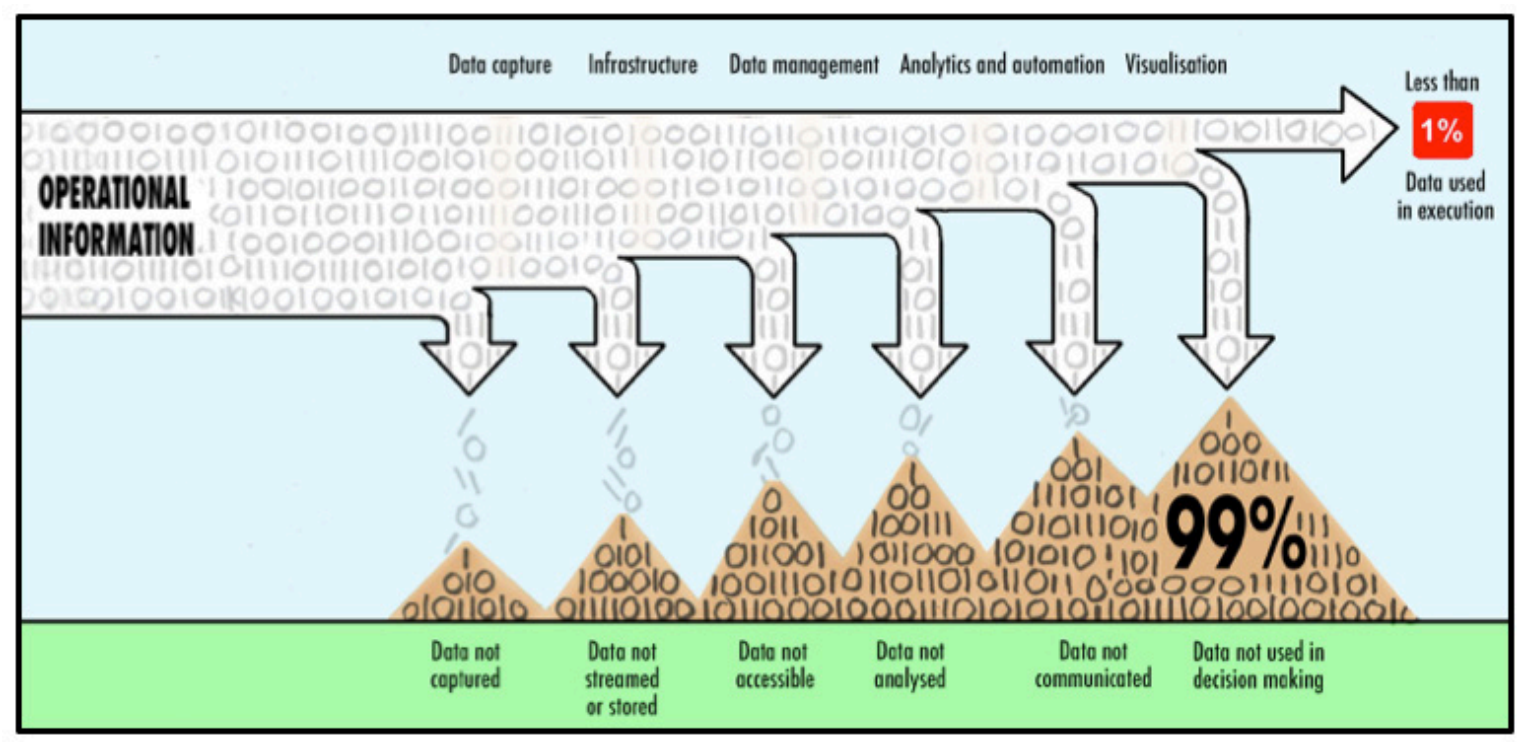

Figure 5 Mining companies use only a fraction of their data (after McKinsey\&Company 2015)

The caving industry is rapidly entering into tougher environments as a consequence of depth of mining, in some cases very high temperatures, high stresses and hard rock with the potential for generating major operational hazards as shown in Figure 6 (Flores 2019; Rojas \& Balboa 2017). All of these challenges will increase the variability of the caving processes impacting on safety, productivity, sustainability and profitability.

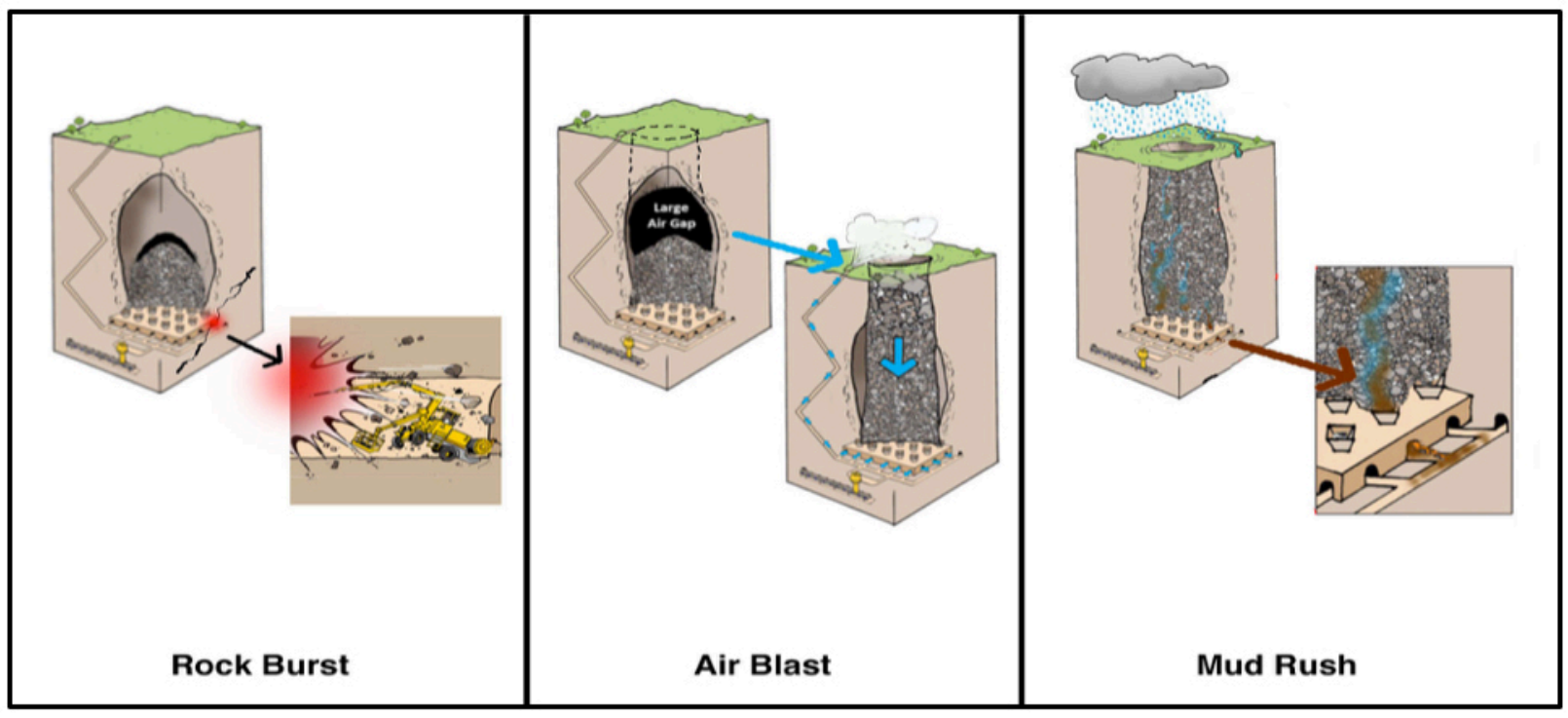

Figure 6 Major caving hazards (Flores 2019) 
The current operational model needs to be transformed into an agile operating, integrated, dynamic business value driven model through local optimisation with digital technologies.

\subsection{Enhanced operational model}

The value add of this enhanced operational model will initially be through local optimisation or automation of some of the key parameters of the caving processes. This local optimisation step can be achieved in the short term (6 to 12 months) through implementation of available digital technologies in some areas where there are understood bottlenecks or gaps that compromise safety and/or cause production disruptions. Indeed, there are many initiatives already being actively pursued in the caving industry such as semiautonomous LHDs, remote drilling and charging and, remote secondary breakage activities. In some cases, projects would have been implemented in the business yet may been stalled or under-delivered due to reasons such as insufficient resourcing, lack of the right capability within the organisations, or poor integration within the current operating model. Therefore, it is very important to have people in the organisations with the motivation, skills and capabilities to enhance the current caving operational model (Sirinanda 2019).

Examples of local optimization technologies ready for broader industry adoption, are:

1. Rapid continuous excavation systems (mechanical excavation equipment)

2. Surface preconditioning by hydrofracturing technique

3. Remote and semi-autonomous equipment (loaders, production drills and explosives charging)

4. Smart sensors for:

a. Equipment health (temperature, oil pressure, tire pressure)

b. Ventilation on demand

c. Caving performance (propagation, air gap)

d. Drawpoint sampling (fragmentation, water and mud)

e. Connecting workforce (tags)

5. Integrated operations centre

6. Data analytics, visualization and simulation

The next step value add of this enhanced operational model will then be in the integrated areas of orebody access, cave establishment and cave production. One example of this enhanced integrated model to increase productivity and business outcomes is the application of cave to mill concept, equivalent to mine to mill in surface mining. Cave to mill is one of the next industry challenges that would help achieve higher mill throughput from finer block cave fragmentation as well as reduce the power consumption at the mill. The latter should integrate the mine and mill to improve the overall cave mining business as shown in Figure 7. 


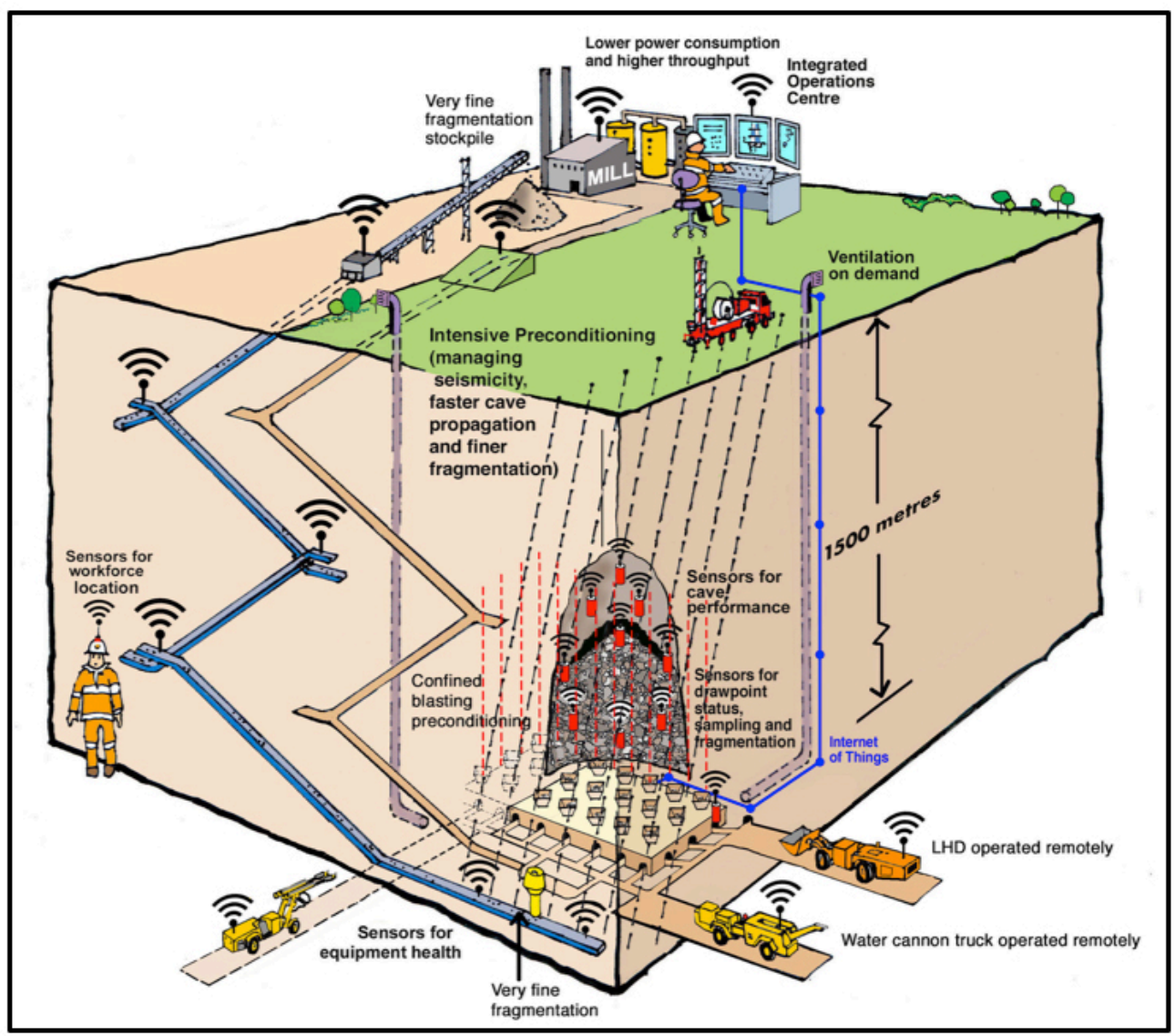

Figure 7 Enhanced operational model - integrated cave to mill application

\subsection{Digital operational model}

The new digital operational model will be based on the use of digital technologies to improve its business effectiveness via a step change in how caving industry operates.

This digital model spans from stochastic geological modelling to the mill stockpile as shown in Figures 8 and 9. It includes modern industrial optimisation from stochastic geological and geotechnical modelling, dynamic mine planning and draw plan, real time cave propagation; ore flow; ore grade; fragmentation and water, equipment performance and health, stockpile surge, people location, integrated operating centres to analytics centres of excellence.

Figures 8 and 9 are presenting the new vision of digital transformation of the cave mining industry. This includes all the enabling technologies to establish the future cave mining operational model. 


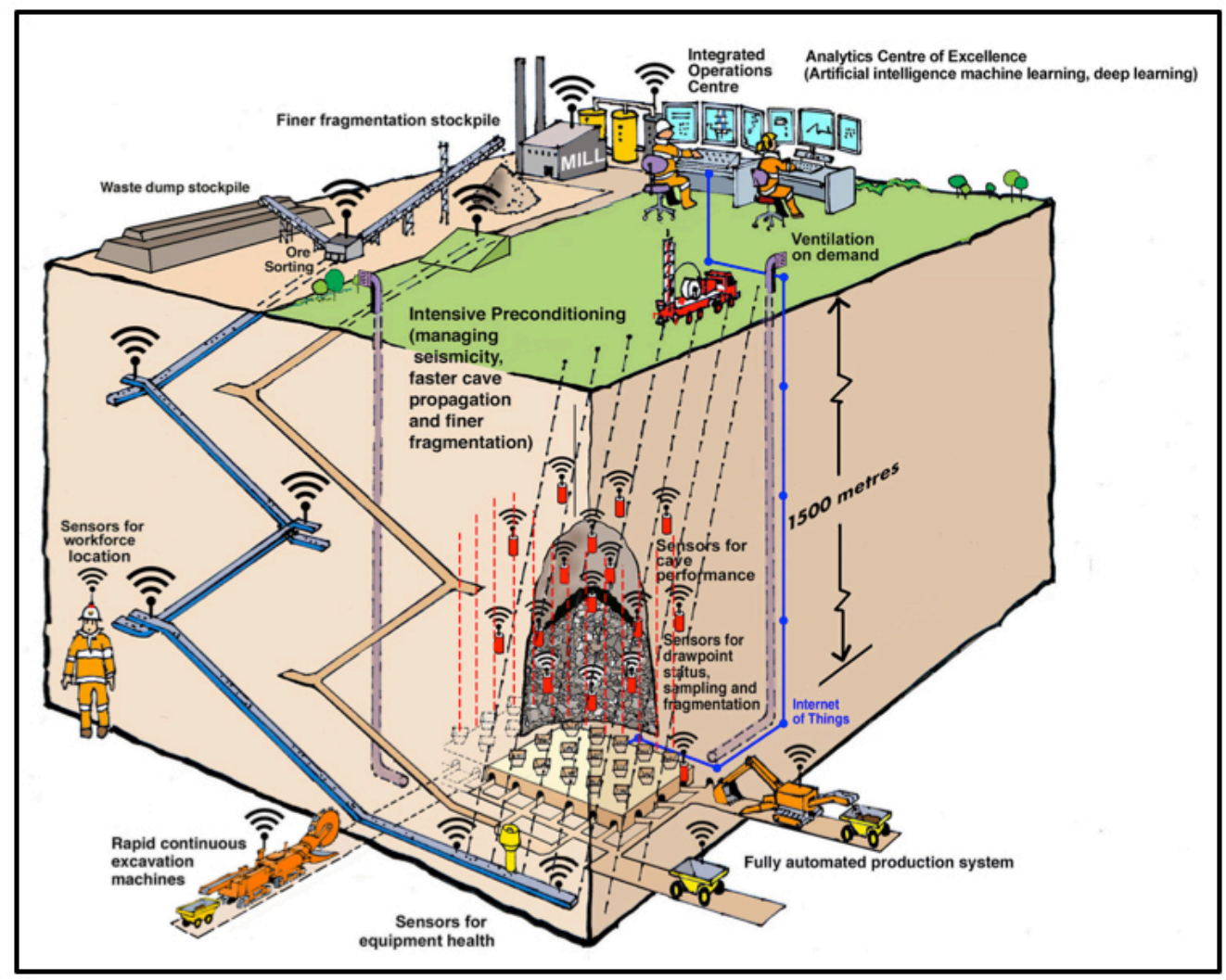

Figure 8

Digital transformation in cave mining - whole caving 'eco-system' data collection

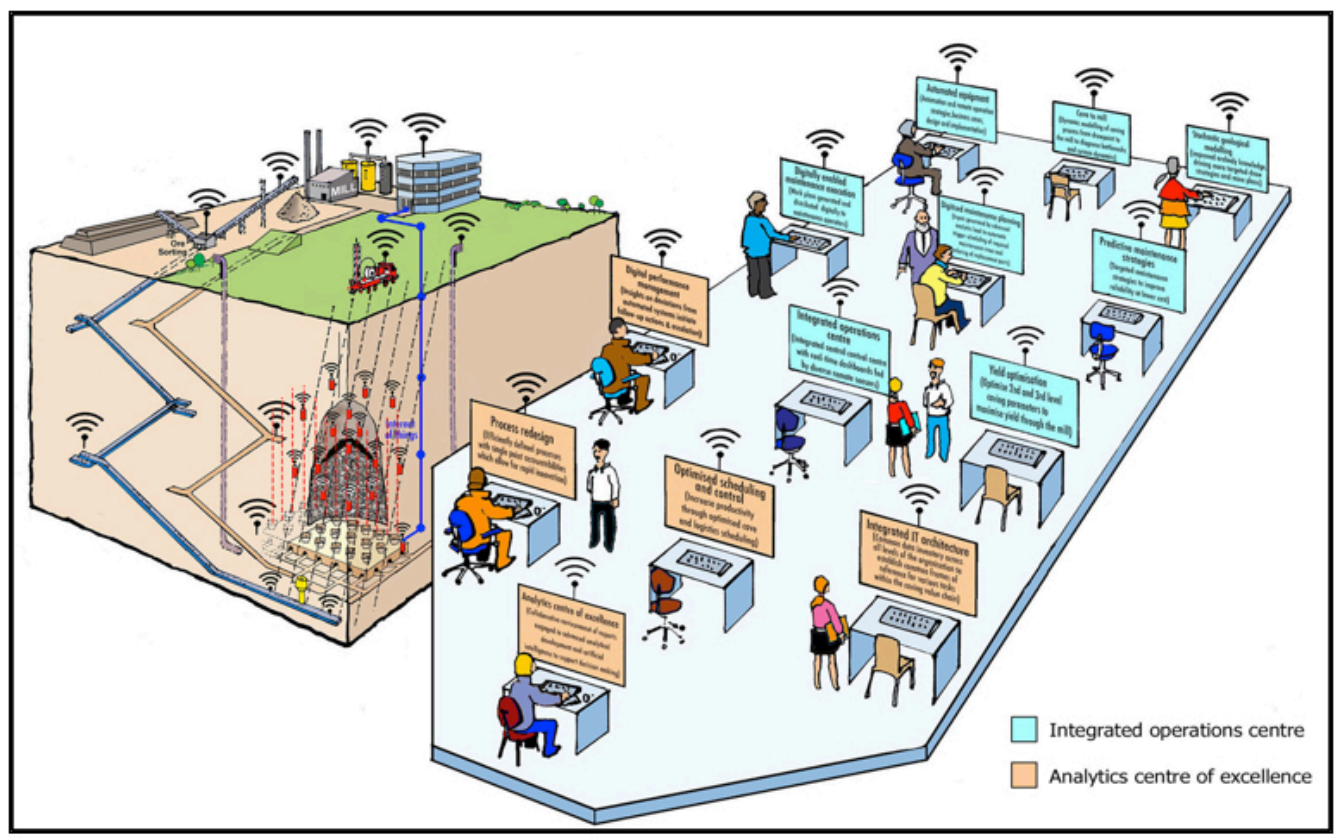

Figure 9 Digital transformation in cave mining - real time decision making and system optimisation 
The digital caving model will allow operation of all the assets at full potential, managing different processes fully integrated across the business, real time data fusion for decision making and mixing of automated equipment in operation (interoperability). This model will also help to address productivity and reduce the variability of the caving processes, as shown in Figure 10. The manufacturing industry is the best example of a sector recognised as a leader in asset productivity as measured by overall equipment efficiency (OEE). By adopting a manufacturing mindset, cave miners can better manage variability and improve productivity (Ernest \& Young 2017). McKinsey\&Company 2015 explained that the mining industry is "at inflection point, in which digital technologies have the potential to unlock new ways of managing variability and enhancing productivity".

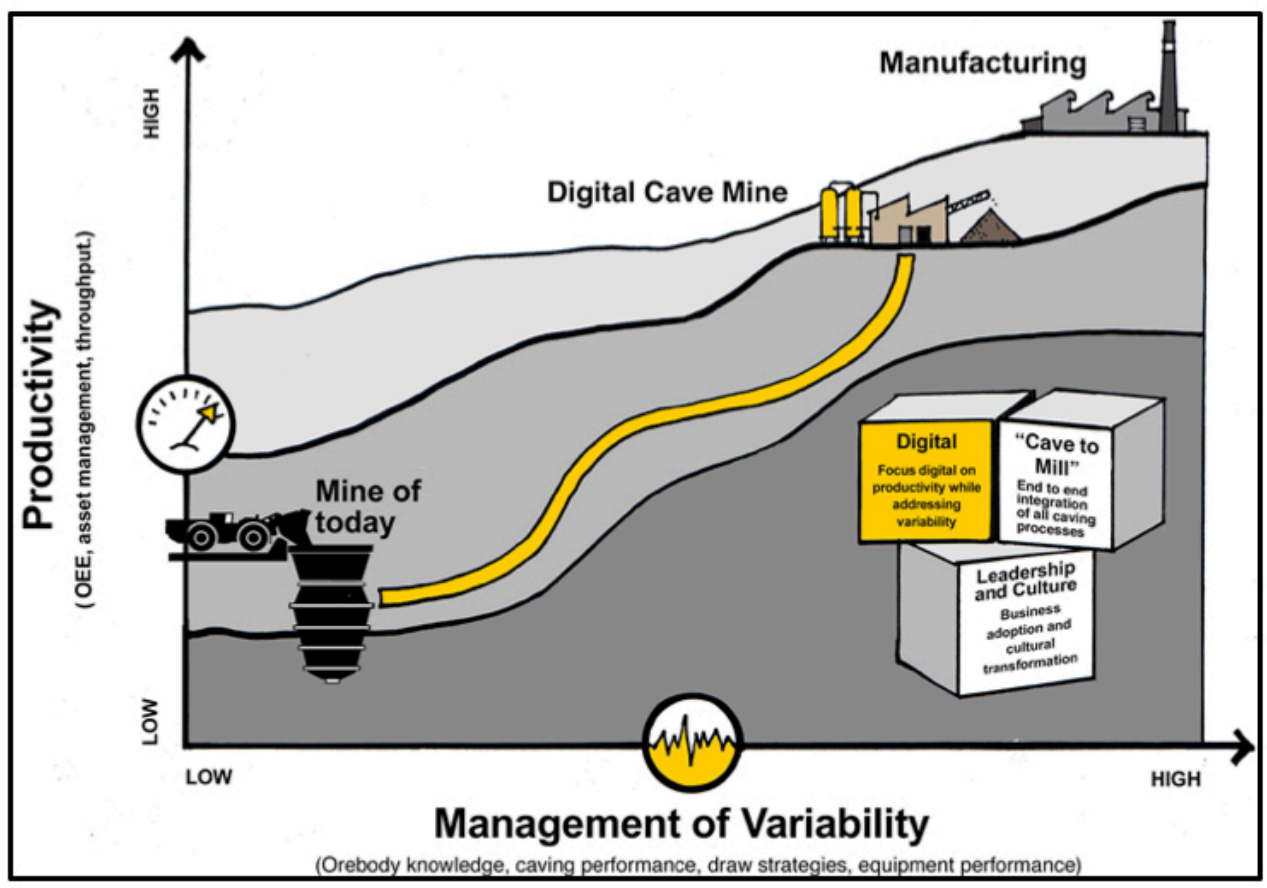

Figure 10 Digital transformation in the cave mining industry to improve productivity and reduce variability (modified from Ernest \& Young 2017)

Additional technologies from the enhanced operational model are required to make the above to happen including:

1. Smart sensors (ore grade, mineralogy, temperature)

2. Fully autonomous equipment

3. Ore sorting

4. Robotics

5. Single pass caving ('undercutless')

6. Internet of Things (IoT)

7. Cloud data storage and compute platforms

8. Data analytics

9. Artificial intelligent (machine learnings, deep learnings)

10. Fit for purpose human capital

This model is an opportunity waiting for adoption into new caving projects that will be in operations in the next 5 to 10 years. Figure 11 summaries the digital transformation process in the cave mining industry.

Yeates 2016 indicated that "the mining industry would have to be described as very immature and only just commencing on the journey toward digital transformation. Whilst this can be seen as a negative 
it can also be seen as a huge opportunity that awaits those who have the strategic vision, courage, commitment and discipline to take the journey".

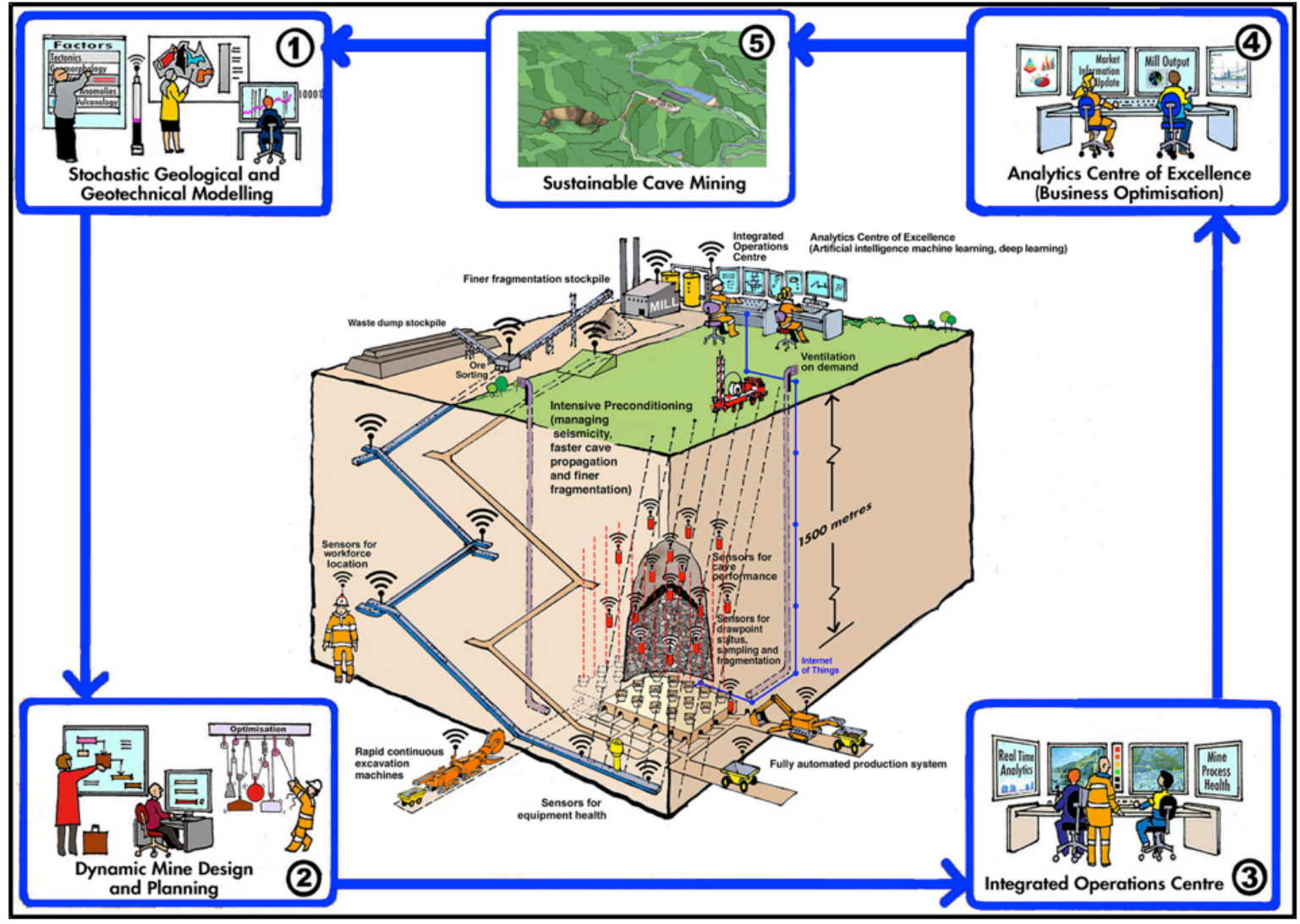

Figure 11 Summary of digital transformation in the cave mining industry

\section{How to achieve digital transformation in cave mining}

To realise digital transformation in cave mining requires engagement, courage and commitment of company top management and boards, upskilling the human capital or workforce, develop an ecosystem, develop specific data platform architecture and engagement of governments and regulators (Deloitte 2017). The focus areas are:

1. Top company management and boards. Digital transformation needs to be supported from the top management level to establish a clear digital strategy, providing funding and resources and getting involved in the management of change processes.

2. Developing a digital strategy and managing the digital transformation. A digital strategy needs to be developed, creating a linkage between safety and productivity with the digital agenda, and understanding the current digital maturity. Digital transformation should begin with an understanding of the desire future state, and the value to be created (Deloitte 2017). Yeates 2016 indicated that it is required leadership to be successful with digital transformation in mining industry. Integration between the traditional Information Technology (IT) organisation, the Operating Technology (OT) organisation and the Technology and Innovation organisation (T\&l) within cave mining companies requires a new organisation structure.

3. Adopting a technology and innovation culture. It will be required to be opened to new thinking and ways of working for the digital era. Leadership, courage and agile culture to support the digital strategy needs to be developed and implemented. 
4. Upskilling human capital. The workforce needs to be trained for the digital transformation. It is also required to establish metrics and incentives to measure effectiveness and outcomes and define clear incentivise for the right behaviours aligned to digital transformation (Deloitte 2018a; Deloitte 2018b).

5. Develop new capabilities. Decisions need to be made to build or buy capabilities for the cave mining transformation.

6. Specific data architecture development. Integration and interoperability of data platform are the most critical elements in the new cave mining digital era.

7. Digital standards are required for the transformation. This includes digital policies and standards focusses on data transparency and security.

8. Develop an ecosystem for digital transformation. This transformation cannot be achieved by a single company therefore requires collaboration between consultants, universities, research centres, governments, regulators, equipment manufacturers, contractors, communities, families and industry partners. Figure 12 shows the ecosystem required for the digital transformation in cave mining industry.

9. Create a roadmap for the transformation. Assess the digital maturity of the companies with interest in cave mining, review the current operating model to identify opportunities to optimise via incremental changes the caving processes. Then, identify the required revolutionary changes to achieve and sustain the digital transformation.

10. Develop a schedule to achieve the defined goals and new normal. A schedule needs to be prepared to ensure that the goals are achieved within the timeframe agreed to and establishing a new business as usual from that point onwards.

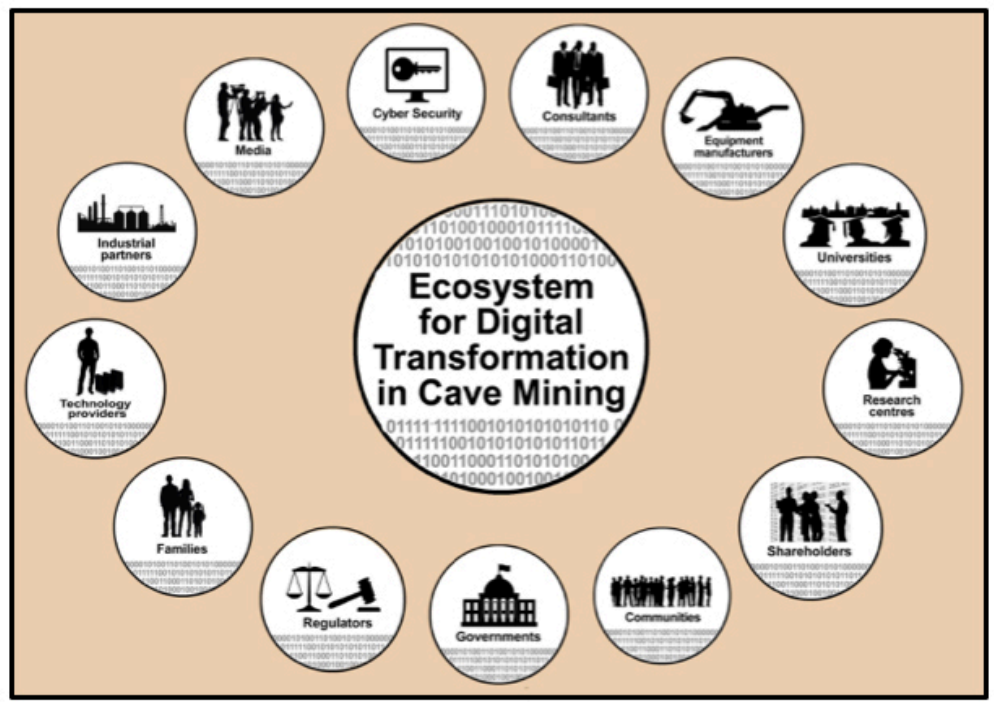

Figure 12 Digital transformation ecosystem 


\section{$4 \quad$ Conclusions}

Historically, the global cave mining industry has advanced in two ways: by increasing the physical scale of operations and by adopting local technologies in some areas to enhance safety and productivity. Today, as the caving industry faces tougher conditions with cave mining margins tightening, many are looking for new ways to improve their efficiency by adding value rather than volume. Digital transformation is already a fact of life for other industries yet not in cave mining. There is an opportunity for cave mining to transform and create new operating models with a more adaptive, agile culture to adopt modern digital technologies to improve safety, productivity, profitability and sustainability. This requires a courageous transformation of the manner of which cave mining is conducted to constitute a new cave mining era.

The roadmap presented in this paper, defines the operational models needed to be developed and implemented to support the new cave mining era. In practice, this transformation will require the caving industry to move from a traditional, localised operating models to agile, integrated, dynamic business value driven models to fostering digital culture to ensure sustainable cave mining.

The future of cave mining requires a complete change in the development of human capital with motivated skill sets to support this new operational model. It is essential to have practitioners in the industry who understand digital strategy and can execute a transformative vision of the cave mining industry. They should be able to see the long-term benefits and implications of adopting technologies such as advanced or smart sensors, internet of things (IOT), artificial intelligence (Al), augmented reality (AR), 3D printing, robotics and others in day-to-day cave mining operations. Future caving mines will need to be low capital, fully autonomous operations and based on whole value chain decision-making. This means that the future cave mining industry will be driven by digital and sustainable business models.

\section{Acknowledgement}

The author would especially like to thank Professor Gideon Chitombo of SMI, The University of Queensland, Australia and Mr. Andrew Logan from Newcrest Mining Limited for the technical discussions and their kind advice and contribution on the preparation of the paper. He also wishes to express his acknowledgements to Newcrest's Future of Mining team for stimulating discussions on this topic. The author would also like to express thanks to Raul Castro from University of Chile for inviting me to be one of the keynote speakers for this conference. Finally, thank you to Jock Macneish and Robert Black from Strategic Images for translating my ideas into illustrations for this paper. The permission of Newcrest Mining Limited to publish this paper is gratefully acknowledged.

\section{References}

Accenture \& Avanade 2015, 'Connected Mine - Optimizing operations at the mine', available from: <https://www.accenture. com/us-en/industries/natural-resources-index>, [4 November 2019].

Catalan, A 2015, 'Implementation and assessment of intensive preconditioning for cave mining applications', PhD Thesis, University of Queensland: Sustainable Minerals Institute, Brisbane.

Deloitte 2018a, 'From here to where? The Mining Matrix', available from: <https://static1.squarespace.com/ static/559e2aa1e4b036f55225a600/t/5b6bb584cd83664ab17daeb6/1533785520649/The+Mining+Matrix+Report. pdf >. [10 September 2019)

Deloitte 2018b, 'Beyond HR: Rethinking work and operations in the mining industry', available from: <https://www2.deloitte. com/content/dam/Deloitte/global/Documents/Energy-and-Resources/human-capital-trends-mining.pdf>. [12 October 2019].

Deloitte 2017, 'The digital revolution: mining starts to reinvent the future', available from: <https://www2.deloitte.com/content/ dam/Deloitte/global/Documents/Energy-and-Resources/deloitte-au-er-digital-revolution.pdf>. [4 December 2019].

Ernst \& Young, 2018, 'Is riding the digital wave key to wiping out your competition?' available from: https://pdfs.semanticscholar. org/24f2/a6d5ba22d5d49bcfe59e7b57886b316ad732.pdf, [10 December 2019]. 
Ernst \& Young, 2017, 'Tomorrow's mine How digital can shape the future?', available from: https://www.ey.com/Publication/ vwLUAssets/EY-tomorrows-mine/\$File/EY-tomorrows-mine.pdf, [10 August 2019].

Flores, G 2019, 'Major hazards associated with cave mining: are they manageable?': Proceedings of Mining Geomechanical Risk 2019, ed. J. Wesseloo, Australian Centre for Geomechanics, Perth, pp 31-46.

Geraghty, R 2016, 'Mining's next performance horizon: Capturing productivity gains from innovation', Proceedings of IMARC 3rd International Mining and Resources Conference, Presentation Document, Melbourne.

McKinsey\&Company 2015, 'How digital innovation can improve mining productivity', available from: <https://www. mckinsey.com/ /media/McKinsey/Industries/Chemicals/Our\%20Insights/How\%20digital\%20innovation\%20 can\%20improve\%20mining\%20productivity/How_digital_innovation_can_improve_mining_productivity.ashx>. [20 November 2019].

Rojas, E \& Balboa, S 2017, 'Management of seismic hazard in high stress condition, El Teniente mine': Proceedings of Rasim 9 Conference, ed. J. Vallejos, University of Chile, Santiago, Chile, pp. 264-273.

Rojas, E \& Landeros, P 2017, 'Hydraulic fracturing applied to tunnel development at El Teniente mine': Proceedings of Rasim 9 Conference, ed. J. Vallejos, University of Chile, Santiago, Chile, pp 236-242.

Sirinanda, K 2019, 'Skills needed for digital mines', available from: <https://mineconnector.com/2019/12/14/skills-needed-fordigital-mines/>. [10 January 2020].

Stock, T \& Seliger, G 2016,'Opportunities of Sustainable Manufacturing in Industry 4.0', Procedia CIRP, vol. 20, pp. 536-541.

Yeates, G 2017, 'The mining industry disrupted', available from: https://www.ausimmbulletin.com/feature/mining-industrydisrupted/. [12 October 2019].

Yeates, G 2016, 'Digital Transformation in the mining industry', available from http://gavinyeates.com/leadership/digitaltransformation-in-the-mining-industry/. [13 November 2019]. 